\title{
ROLE OF MAGNETORHEOLOGICAL FLUIDS AND ELASTOMERS IN TODAY'S WORLD
}

\author{
Paweł SKALSKI*, Klaudia KALITA*
}

"Transport Department, Center of Transportation and Energy Conversion, Institute of Aviation, Al. Krakowska 110/114; 02-256 Warszawa, Poland ${ }^{*}$ Faculty of Mechanical Engineering and Aeronautics, Rzeszow University of Technology, Al. Powstańców Warszawy 8, 35-959 Rzeszów, Poland

\author{
pawel.skalski@ilot.edu.pl, klaud14@gmail.com
}

received 11 August 2016, revised 24 October 2017, accepted 30 October 2017

\begin{abstract}
This paper explains the role of magnetorheological fluids and elastomers in today's world. A review of applications of magnetorheological fluids and elastomers in devices and machines is presented. Magnetorheological fluids and elastomers belong to the smart materials family. Properties of magnetorheological fluids and elastomers can be controlled by a magnetic field. Compared with magnetorheological fluids, magnetorheological elastomers overcome the problems accompanying applications of MR fluids, such as sedimentation, sealing issues and environmental contamination. Magnetorheological fluids and elastomers, due to their ability of dampening vibrations in the presence of a controlled magnetic field, have great potential present and future applications in transport. Magnetorheological fluids are used e.g. dampers, shock absorbers, clutches and brakes. Magnetorheological dampers and magnetorheological shock absorbers are applied e.g. in damping control, in the operation of buildings and bridges, as well as in damping of high-tension wires. In the automotive industry, new solutions involving magnetorheological elastomer are increasingly patented e.g. adaptive system of energy absorption, system of magnetically dissociable [hooks/detents/grips], an vibration reduction system of the car's drive shaft. The application of magnetorheological elastomer in the aviation structure is presented as well.
\end{abstract}

Key words: Damper, Magnetorheological Fluid, Magnetorheological Elastomer, Smart Material, Shock Absorber, Application

\section{INTRODUCTION}

Scientists working in the area of material science, are contributing to the development of new materials or discovering new properties of already known materials. The 80's of the XX century were the beginning point of a rapid increase of interests in materials, which were named smart (Carlson, 2001; Kaleta, 2013; Bajkowski, 2014). This group of materials includes magnetorheological fluids and elastomers, which are characterized by the fact that they change their rheological properties under the influence of a magnetic field (Carlson 1999). The presented magnetorheological materials are very useful in solving damping problems, which are one of main engineering dilemmas of construction and exploitation of machines and devices (Bajkowski, 2014). A damper is a mechanical device that has a dulling or deadening influence. Shock absorber, or shock damper is what you call a mechanism used for absorbing or partially eliminating the energy of sudden impulses or shocks in machinery or structures (Carlson, 1994). Dampening devices have been around for a long time, even in early transportation means such as carriages. These devices have remained relevant for years, and with the fast development of technology, there is a constant need to improve and revolutionize dampening mechanics. An example of developments in dampening devices is the use of materials such as magnetorheological fluids, which have been used to create dampers with better functionality and performance. Magnetorheological dampers have a very broad range of use, from seismic response reduction, to shock absorbers used in vehicles in order to provide comfortable riding over a rough terrain, or in bumpers of automobiles for reducing impacts during accidents (Imthiyaz, 2014; Li et al., 2016; MAGNERIDE ${ }^{\mathrm{TM}}$ Controlled Suspension System, 2013; http://robohub.org/icelands-ossur-wins-popsci-best-of-whats-new- award-for-symbionic-leg/). These fluids, however, have a series of disadvantages (sedimentation, sealing). This encouraged new solutions using magnetorheological elastomers, which overcome some of the difficulties which MR fluids create. One of the main assets of MR elastomers is the lack of sedimentation, as the ferromagnetic particles are embedded in a polymer matrix, which gives them a small range of motion. The achievable yield stress in MR fluids is also something that raises concern, as these smart fluids typically work in the post- yield region, while MR elastomers work in the pre-yield region. To add to that, MR elastomers do not need channels or seals to hold or prevent leakage, as they have a solid state of matter (Kaleta, 2013).

These smart materials, however, are not only useful in dampening technology, but also in motor shaft sealing mechanics, industrial treatment of polished surfaces, medicine, vibration isolation and more (Bajkowski, 2004; Bajkowski, 2005; Bajkowski, 2006; Bajkowski, 2007; Bajkowski, 2014; Goncalves, 2005; Griffin, 1998; Lee et al., 1999; Lee et al., 2009; Milecki, 2001; Milecki, 2004; Milecki et al., 1999).

In the second Section the magnetorheological fluids and magnetorheological elastomers are described. Then, in the third Section the applications of such smart materials are shown. At the end, the paper is concluded.

\section{SMART MATERIALS - MAGNETORHEOLOGICAL FLUIDS AND ELASTOMERS}

As new technologies are being developed, smart materials have found a large number of applications over the years. These materials are unique, as their properties can be changed by an external stimuli. In the case of magnetorheological fluids and 
elastomers, viscoelastic and rheological properties can be controlled by the application of a magnetic field (Schwartz, 2009). Thanks to their specific characteristics, these materials create the ability to build systems with adaptive properties, which was impossible to achieve with conventional materials (Kaleta, 2013).

\subsection{Magnetorheological fluids}

MR fluids state of matter can be changed with the use of different levels of a magnetic field. These fluids are composed of magnetic particles suspended in a viscous fluid. With the absence of a magnetic field these fluids have a low viscosity, as the particles are not arranged. The particles are of a small size, measuring between 3 and 10 microns (Tao, 2011). The magnetic particles of an MR fluid are additionally covered with a special layer, enhancing their magnetic susceptibility and reducing their tendency to form aggregations. Other substances, including anticorrosion and anti-sedimentation substances, are also added in small amounts. The influence of a magnetic field causes changes in the physical properties of an MR fluid.The application of such a field forces the particles to acquire a magnetic dipole, and to then to move and align themselves along the lines of the magnetic flux. This change in the material appears as a rapid increase in apparent viscosity and the fluid developing into a quasi-solid state. The fluid develops controllable yield strength, while the change depends on the size and strength of the magnetic field, as well as the composition of the fluid. After the disappearance of an external magnetic field the liquid returns to its baseline. The structure of magnetorheological fluids, and the behavior of the fluids under no magnetic field and with applied magnetic field applied are presented in Fig. 1. Changes under the influence of a magnetic field appear in less than 10 milliseconds. Magnetorheological fluids retain their properties in the temperature range of $-40 \div 150\left[{ }^{\circ} \mathrm{C}\right]$, while the yield point value for these liquids is in the range of $50 \div 100$ [kPa] (Carlson and Weiss, 1994).
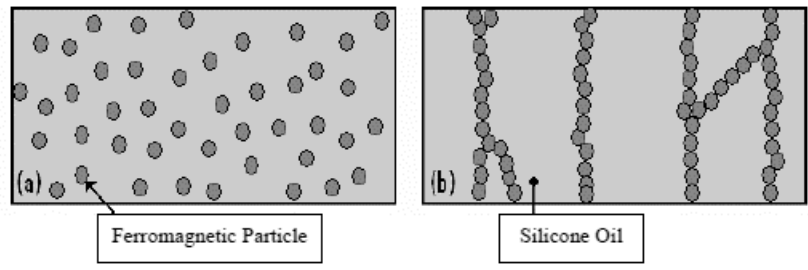

Fig. 1. Structure of magnetorheological fluids, ferromagnetic particles in a silicone oil suspension; (a) under no magnetic field, and (b) with magnetic field applied

Due to a difference in density and the force of gravity, the magnetic particles in a magnetorheological fluid settle out of the fluid in which they are entrained, making it lose its magnetic properties. Sedimentation is one of the greatest disadvantages of these smart materials, as additional measures have to be taken, e.g., introducing a single-walled carbon nanotube (SWNT) in $\mathrm{Cl}$ based MR fluid (Fang et al., 2007), to create a device which overcomes this problem. Another problem that has to be dealt with is potential leakage into unwanted areas of the mechanism and thickening after prolonged use which creates the need of replacement. Nevertheless, the application set for MR fluids is vast, thanks to its precise controllability and dynamic response.

\subsection{Magnetorheological elastomers}

Magnetorheological elastomers generally consists of a natural or synthetic rubber matrix interspersed with micron sized (typically 3 to 5 microns) ferromagnetic particles. Elastomers such as rubber are used as they are generally soft and/ or deformable at room temperature, elastomers can have the ability to reversibly extend from $5-700 \%$ depending on the specific material. Thanks to a specially designed structure, the magnetic particles cannot move freely within the matrix. Therefore, there is no sedimentation. Magnetic field application stimulates a non-linear and reversible change of some of the properties. The limited movement of particles results in a quicker response to a magnetic field than in MR fluids. Magnetorheological elastomers work in the post-yield region, which differentiates them from MR fluids. There are two main types of MR elastomers: polarized elastomers (anisotropic) which have a strictly organized internal structure and isotropic elastomers (Kaleta, 2013). The difference between these two kinds of MR elastomers, is that, during the production of anisotropic elastomers, an external magnetic field is applied. Fig. 2. presents a SEM image of the two types of MR elastomer. a)

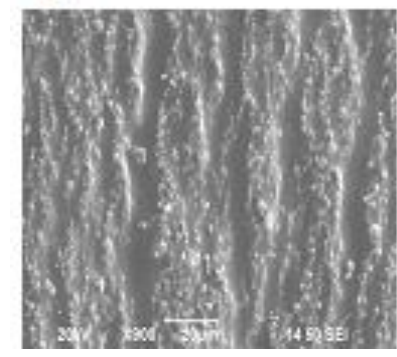

b)

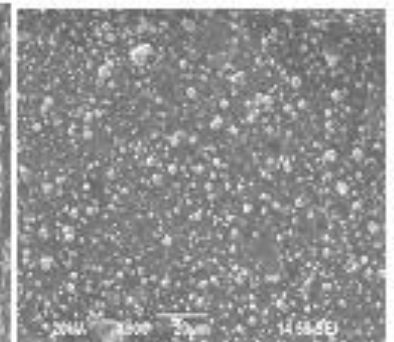

Fig. 2. SEM images of MREs: a) anisotropic MRE ; and b) isotropic MRE (Li et al., 2013)

What distinguishes anisotropic MR elastomers from MR fluids is that when the external magnetic field is removed, the anisotropic structure remains. The goal in the MR elastomers design is for the applied magnetic field to cause the greatest possible change in the materials properties. The size and shape of the magnetic particles, as well as the volume ratio of the magnetic particles to the matrix's material, have an important impact on the rheological effect (Kaleta, 2013). MR elastomers unique characteristics are what makes them have big market potential (Li et al., 2013).

\section{MAGNETORHEOLOGICAL SMART MATERIALS IN APPLICATIONS}

\subsection{Applications of magnetorheological fluids}

MR fluids have been found very useful in shock absorbers or dampers. These dampers are filled with a magnetorheological fluid, which, after the application of an external magnetic field changes from liquid to semi solid state, allowing the dampening characteristics to be controlled by the field. One of its main uses is 
in semi-active vehicle suspensions which can adapt to road conditions (Carlson et al., 2000). One of the leaders in MR fluid technology in vehicle suspensions is LORD corp., which is the exclusive supplier of MR fluid technology to BWI for their Magneride primary suspension system for automotive applications. These systems are now used on more than 1,000,000 vehicles from multiple automotive OEMs including Ferrari, Audi, GM, Land Rover and others. Their MR fluids are of very high quality, advocated of having a fast response time, dynamic yield strength, temperature resistance as well as a hard settling resistance (Int. 1). This increase in commercial interest is largely due to the success of research projects and through the efforts of Lord Corporation. Schematics of LORD MR dampers are presented in Fig.3.

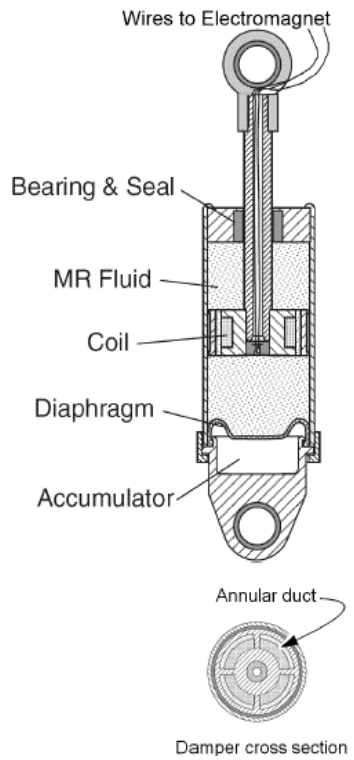

Fig. 3. Schematic of single ended MR damper and double ended MR damper, both produced by Lord (Spaggiari, 2013)

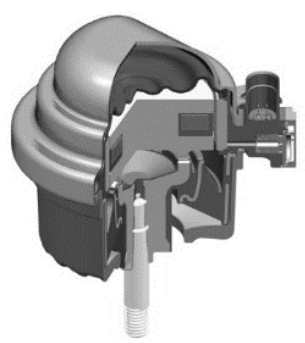

Fig. 4. BWIGroup powertrain mount using magneto-rheological technology (Magneto-Rheological Mounts, 2013)

Extensive analysis of the properties of magnetorheolgical fluids is included in Seval Genc's thesis (Genc, 2002), and the work of Fernando D. Goncalves (Goncalves, 2005). More information on MR fluids' properties can also be found in works: (Rabinow, 1948; Rabinow 1951; Nyawako and Reynolds, 2007).

BWIGroup, a leading global supplier of ride control systems, has introduced into production a powertrain mount using magneto-rheological technology (Fig. 4). The mount contains an electromagnetic coil that can generate a variable magnetic flux across the fluid passages. When the coil current is off, the MR fluid is not magnetised, the iron particles are randomly dispersed within the fluid, and the fluid behaves like conventional hydraulic oil. When the coil is energized, the magnetic field causes the particles to align into fibrous structures in the direction of the magnetic flux. The strength of the bond between the particles in the structures is proportional to the strength of the magnetic field, so changing the current provides real-time variable damping with a very large range of force variation (Fang et al., 2007).

Dampers and shock absorbers are used for example in vibration security systems, exploitation of buildings and bridges (Dyke et al., 1996; Dyke et al., 1998; Gordaninejad, 2002; Hiemenz and Wereley, 1999), and also in damping of vibrations of high - voltage wires (Sapinski et al., 2006; Sapinski and Snamina, 2007). The Dr. Franjo Tudjmann Bridge near Dubrovnik in Croatia has adaptive cable dampers installed which significantly reduce the oscillation amplitudes of the cables (Fig. 5.) (https://www.dywidagsystems.com/emea/projects/project-details/article/dr-franjo-tudjma nn-bridge-dubrovnik-croatia.html).

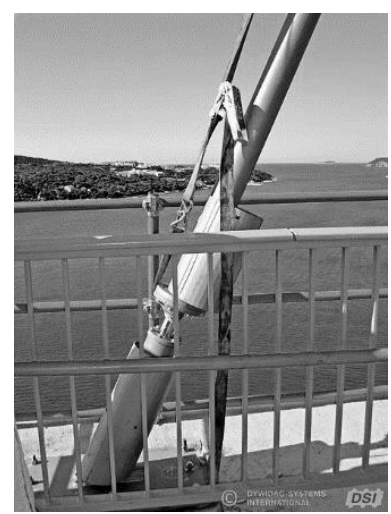

Fig. 5. Cable vibration dampers based on MR fluid technology (https://www.dywidag-systems.com/emea/projects/projectdetails/article/dr-franjo-tudjmann-bridge-dubrovnik-croatia.html)

Magnetorheological dampers are also used in the process of vibration damping of car's suspension (Fig. 6) (Int. 3), in driver's seats in large trucks, to reduce harmful vibration that are transferred to the human body (Sassi et al., 2005; Park and Jeon, 2002), as well as in the construction of washing machines (Fig. 7). A simple, inexpensive magnetorheological fluid sponge designed for incorporation into washing machines consists of a steel bobbin and coil surrounded by a layer of foam saturated with MR fluid. The elements constitute a piston on the end of the shaft that is free to move axially inside a steel housing that provides the ma netic flux return path. The damping force is proportional to the sponge's active area (Carlson, 2002).

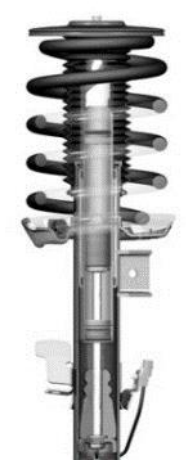

Fig. 6. MagneRide controlled suspension system-magneto-rheological damper technology (MAGNERIDE ${ }^{\mathrm{TM}}$ Controlled Suspension System, 2013) 


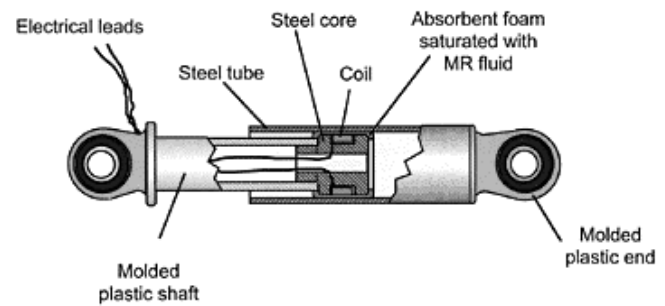

Fig. 7. Inexpensive magnetorheological fluid sponge designed for incorporation into washing machines (Carlson, 2002)

Because of the possibility of changing their physical quantities, these fluids find use in sealing technology in different mechanical elements, such as, motor shafts working under special conditions, e.g., in mines, ventilator shafts and in elements of bioreactors and chemical reactors, and other mechanical elements. They are also used in precise industrial processing of polished surfaces (Bajkowski, 2014). The sealing system presented in Fig. 8 consists of a permanent magnet 3 placed between two rings with a high magnetic permeability 4 . The magnetic flux penetrates the rings 4 MR fluid 5 shaft 6 and ring 2 or bearing 7 (Muc and Barski, 2007).
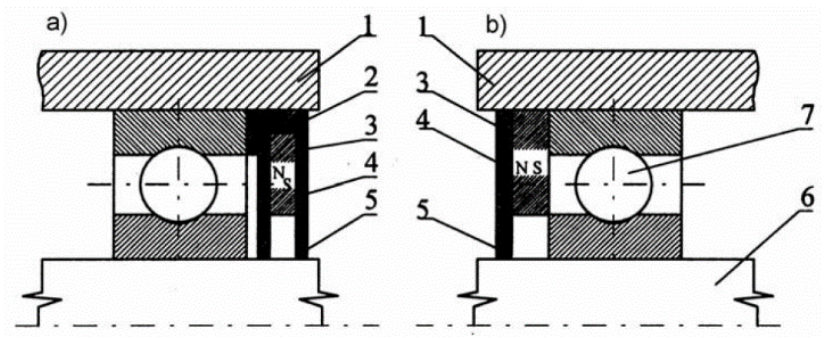

Fig. 8. Schematic of a sealing system in a motor bearing element with the use of MR fluids (Muc and Barski, 2007) a)

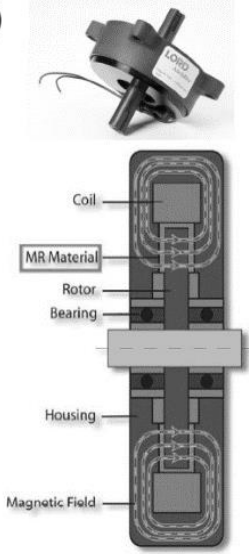

b)

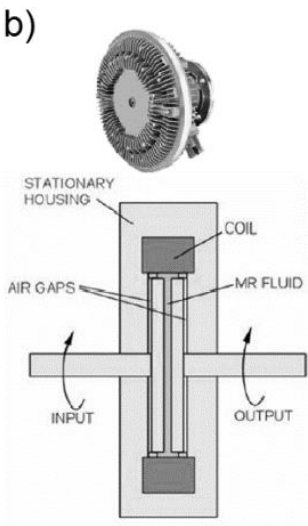

Fig. 9. Picture and schematic of a) MR based brake and b) clutch, both produced by Lord (Spaggiari, 2013)

Magnetorheological fluids are also used in the production of magnetorheological composites (Kaleta and Lewandowski, 2007; Kaleta et al., 2007), in the construction of clutches and brakes (Fig. 9) (Kikuchi et al., 2009; Kikuchi et al., 2010; Park et al., 2008; Spaggiari, 2013), robots (Yoon et al., 2003), in CD and DVD drives (Szelag et al., 2000), in medical activities, such as devices for rehabilitation (Avraam, 2009; Carlson, 2001), or invitro methods (Flores and Liu, 2002), in printing (Muc and Barski,
2007), in suspension of planes and helicopters (Skorupka, 2010), in the construction of guns (Poynor, 2001; Bajkowski M., 2006).

Intensive work is being conducted on the broad use of magnetorheological fluids in medicine, especially orthopedics (Bajkowski, 2014). Examples are shown in Fig.10 and Fig. 11.

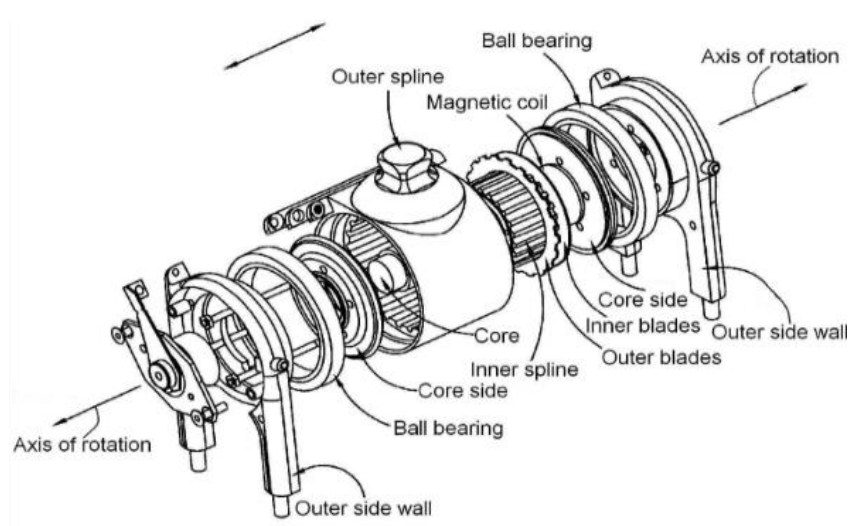

Fig. 10. A detailed exploded perspective view of a magnetorheologically actuated prosthetic knee (Thorarinsson, 2006)

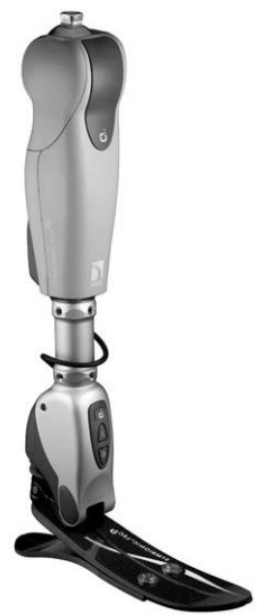

Fig. 11. The microprocessor-controlled Rheo Knee This is the first prosthetic component to use magnetorheological fluid to contro joint resistance (http://robohub.org/icelands-ossur-wins-popscibest-of-whats-new-award-for-symbionic-leg/)

Another example of MR fluid application is in the stabilization of knee joints, elbows, and ankles after an operation or injury. The pressure applied to these joints can be controlled by magnetorheological dampers, which can help speed up the process of rehabilitation (Bajkowski, 2014).

There is also potential for MR fluid dampers to be used in aviation, with ongoing work on the application in the rotary wing industry to isolate vibrations from the aircraft structure and crew (Forte et al., 2004). There are three different ways in which MR fluid can be used: squeeze mode, valve mode and shear mode. The mode used depends on the designation of the damper. A device that uses squeeze mode has a layer of MR fluid that is placed between paramagnetic pole surfaces, while devices operating in shear mode have when a layer of MR fluid between two paramagnetic moving surfaces. Flow mode uses MR fluid to impede the flow of MR fluid from one reservoir to another. This last mode can be used in dampers and shock absorbers, by using the movement to be controlled to force the fluid through 
channels, across which a magnetic field is applied (Olabi and Grunwald, 2007; Poynor, 2001). Aside from the other disadvantages of MR fluids mentioned previously, they also tend to be expensive and are still a limited feature.

More information about magnetorheological fluids and their applications can be found in the book J. Bajkowskiego (Bajkowski, 2014), and other publications (Skorupka, 2010; Kaleta, 2013; Milecki and Lawniczak, 1999; Sapinski, 2006; Goncalves, 2005; Schwartz, 2009; Muc and Barski, 2007; Carlson and Jolly, 2009; Spaggiari, 2013; Skalski, 2014; Tao, 2011; Genc, 2002).

\subsection{Applications of magnetorheological elastomers}

In comparison to MR fluids, MR elastomers are not widely used as dampening devices. Because of some of the downsides that MR fluids present, MR elastomers are starting to receive attention, as they have many potential engineering applications ( $\mathrm{Li}$ et al., 2014). They have found function in developing adaptive tuned vibration absorbers and vibration isolation systems, since their stiffness changes within a magnetic field (Spaggiari, 2013; Carlson et al., 2000). A variable stiffness absorber based on magneto-rheological elastomer was designed, its features were published by The Transactions of Nonferrous Metals Society of China in 2009. Active and semi active vibration isolation systems based on magnetorheological materials were also created (Bazinenkov et al., 2004; Xiao et al., 2009; Spencer et al., 2007). The devices shown in Fig. 12 and Fig. 13 use coils to generate the magnetic field. There are, however, few designs of dampers using MR elastomer technology.

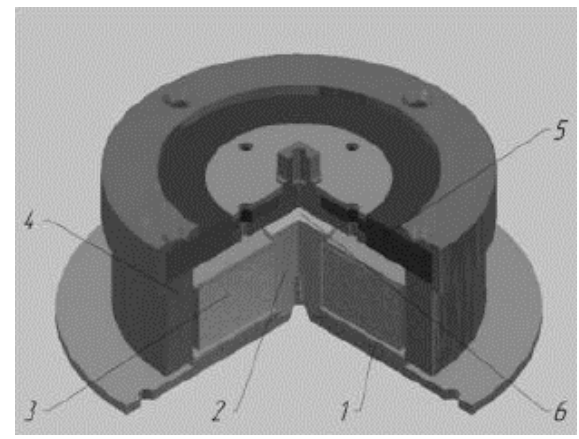

Fig. 12. The design of the damper based on MR elastomer: 1 - foundation, 2 - magnetic core, 3 - electromagnetic core, 4 - magnetic conductor rings, 5 - membrane of the MR elastomer, 6 - air gap (Bazinenkov et al., 2004)

Magnetorheological elastomers have a big potential, which can be used in the motorization industry. One of the solutions which includes MR elastomer is a patent (Watson, 1997) owned by Ford Motor Company, concerning the regulation of the suspension elements stiffness by implementing a sleeve with adjustable rigidity. In this solution, the magnetorheological elastomer is placed in between two sleeves; the one located inside is connected with the moving parts of the suspension, and the one on the outside is connected with the bodywork. An additional part of the system is a coil located in between the composite and the inside cylinder. The rigidity of the magnetorheological composite is regulated with the coil in which the magnetic field is induced. This solution can reduce the oversteer and understeer of a vehicle and can reduce the noise generated by the vibrations of a car body.
A similar solution was used to eliminate the vibrations of brake discs (Stewart, 1998). The previously described element consisting of the two cylinders' discs with a layer of magnetorheological elastomer in between them was used in this method. Rigidity of the composite changes as the electric current going through the coil (which is reeled around the layer of elastomer) varies. The current value is set by the control system based on the data received from the sensor in the braking system.
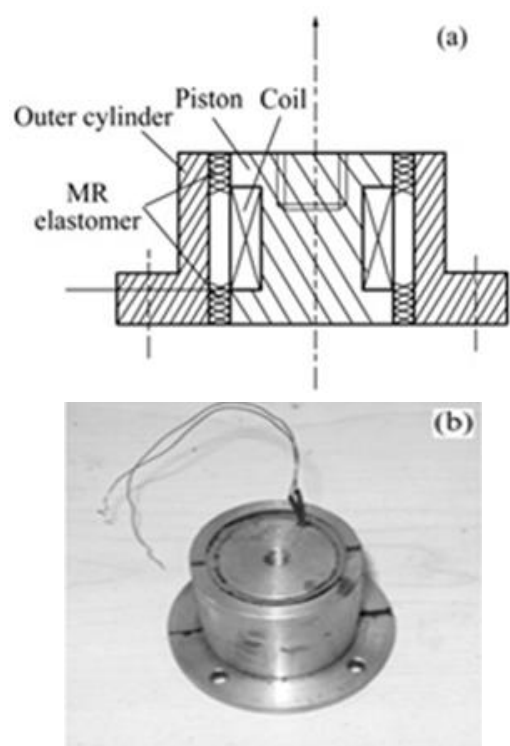

Fig.13. Schematic configuration (a) and photograph(b) of MRE absorber (Xiao et al., 2009)

A method of fast regulation of the physical properties of the elastomer elements in cars can be found in literature available on this topic (Elie, 1999). In traditional solutions the elastomer parts, such as, sleeves in the suspension, parts of the engine fastening, the propulsion transfer system and exhaust system have unchangeable physical properties. By replacing them with magnetorheological elastomer and adding a control system, it is possible to vary their rigidity, and therefore to adjust the level of noise and vibration, moreover to eliminate dipping of the car during braking, oversteer and understeer.

Thyssen Krupp AG company has developed a steering wheel column with an adaptive system of energy absorption in case of a crash, in which magnetorheological elastomer is applied to one of the elements (Klukowski, 2009). This solution differs from the previous one which has a metal element responsible for energy absorption. Due to the implementation of MRE, the new solution accommodates factors such as the vehicle's velocity and driver's mass.

General Motors has developed a system which absorbs energy during a crash (Barvosa-Carter, 2006). It can be installed inside headrests, seats, the dashboard, doors or over driver's and passengers' heads. This patented solution is composed of a rigid base and an elastic cover. In between them are the cylindrical elements made of magnetorheological elastomer with the coil reeled on them. The whole system is equipped with sensors and a control system.

Fig. 14 illustrates the reversibly expandable energy absorbing assembly in a pre-deployed, i.e. a stowed or original configuration. An exemplary reversibly expandable energy absorbing assembly, generally indicated as (10), utilizing actively controlled and engi- 
neered materials comprises a flexible covering (12) attached to a rigid support structure 14 (Barvosa-Carter, 2006).

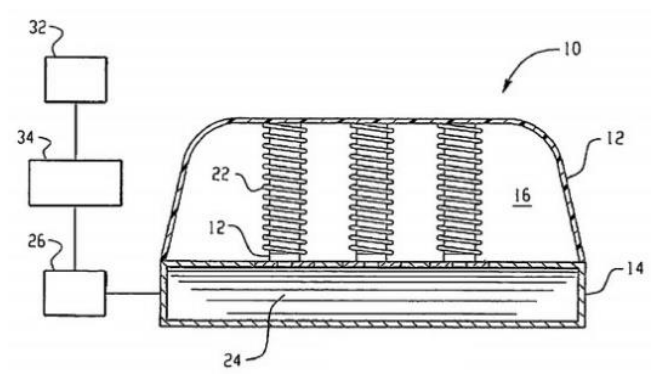

Fig. 14. A schematic illustrating an energy absorbing assembly in a stowed or pre-deployed configuration in accordance with the present disclosure (Barvosa-Carter, 2006)

Automotive companies have patented solutions which can have applications not only in the motorization industry, but in others as well. For instance, GM has developed a system of magnetically dissociable [hooks/detents/grips] which contains MR elastomer in its conformation (Ottaviani, 2006). This particular system can be used for vibration elimination.

Detents, which are opened and closed with the use of a magnetic field, were used to develop an entire system of separable securing of the various components of the car, for example closing the trunk lid or doors (Ottaviani, 2006). The proposed solution makes closing and opening of the lid easier, as well as absorbs more energy in case of an accident than the traditional singlepoint locks. As shown in Fig. 15 a releasable fastener system, generally indicated as (10), comprises a loop portion (12) and a hook portion (14). The loop portion (12) includes a support (16) and a loop material (18) disposed on one side thereof whereas the look portion (14) includes a support (20) and a plurality of closely spaced upstanding hook elements (22) extending from one side thereof. The hook elements (22) are formed of a magnetorheological elastomer that provides a shape changing and/or flexural modulus capability to the hook elements (22). The description can be find in (Ottaviani, 2006).

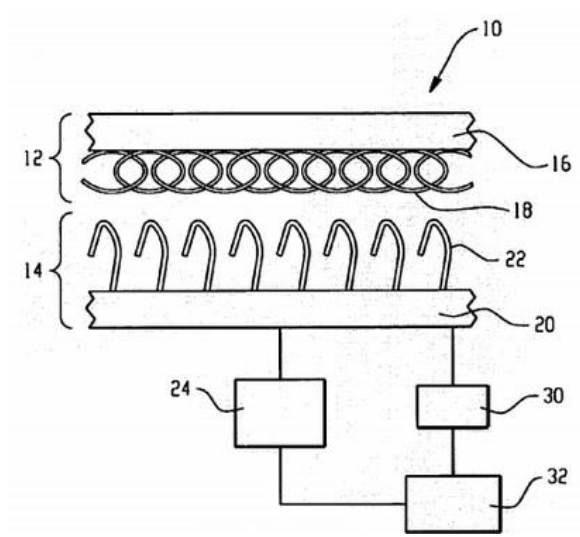

Fig. 15. A cross sectional view of a releasable fasting system (Ottaviani, 2006)

In the automotive industry, magnetorheological elastomers are used in the construction of engine covers or boots, for instance (Brei et al., 2006). In the proposed solution developed by General Motors Corporation and the University of Michigan, the cover, which in normal operation is close to the engine or luggage, deforms in the instance of a crash in such a way that it increases energy absorption.

Magnetorheological elastomer may be used as such a skin. Research is being done on the content of carbonyl iron particles, which are responsible for changing the rheology of the material in the presence of an external magnetic field. The first tests have shown that the properties of the material can be controlled by varying the external magnetic field. The process is completely reversible and the magnetorheological material bodes well in constructional solutions made of morphing structures. Fig. 16 shows a new magnetorheological elastomer destined for use in aviation structures (Skalski, 2014).

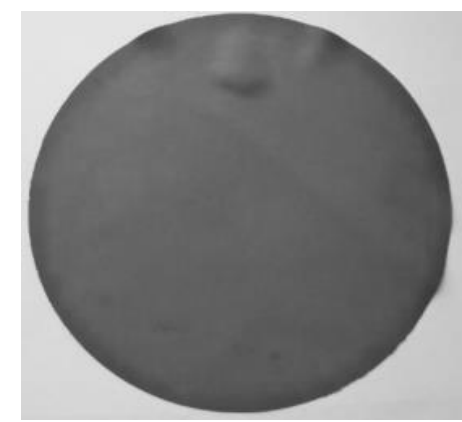

Fig. 16. View of a magnetorheological skin (Skalski, 2014)

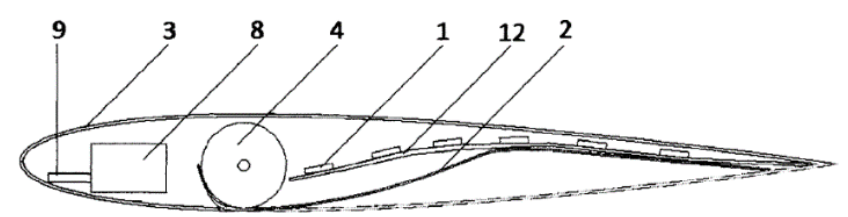

Fig. 17. A schematic view of the morphing structure with a magnetorheological elastomer (Skalski et al., 2014)

In the reported Polish patent (Skalski et al., 2014) an airfoil with a variable shape was described. It has an elastic coating made from an active material (magnetorheological elastomer) allowing to change the aerodynamic characteristics of an aircraft wing or a rotary blade during flight. In this solution (Skalski et al., 2014) presented in Fig.17, a thin layer of magnetorheological elastomer (2) was placed on the upper side of the reversed wing (3). Magnets (1) were placed underneath this surface (12) in order to generate a strong magnetic field that would attract the MR elastomer (2) and therefore change the overall profile of the wing. One end of the MR elastomer (2) is connected to a shaft (4), second end is fixed to the wing (3). The control module (9) is connected to the power supply (8). The control module controls (9) the servomechanism (Skalski et al., 2014).

\section{CONCLUSIONS}

To sum up, as new technologies are being developed, magnetorheological fluids and elastomers have found a large number of applications over the years. These materials are unique, as their properties can be changed by an external stimuli. In the case of magnetorheological fluids and elastomers, viscoelastic and rheological properties can be controlled by the application of an magnetic field. Thanks to their specific characteristics, these 
materials create the ability to build systems with adaptive properties, which was impossible to achieve with conventional materials.

These smart materials are used e.g. in dampers, shock absorbers, clutches and brakes. Magnetorheological dampers and magnetorheological shock absorbers are applied e.g. in damping control, in the operation of buildings and bridges, as well as in damping of high-tension wires.

New solutions which regard implementing magnetorheological elastomers for automotive applications are constantly being patented/ licensed.

In the aerospace industry magnetorheological elastomers are desirable for use in morphing structures. Morphing in aerospace applications is becoming more and more popular due to the possibility of increasing the productivity and efficiency of flight. With MR elastomers, the development of new aircraft structures becomes possible. The main challenge for the next years and decades will be to adapt, at industrial level, developments made in laboratories, like new structures with more flexibility and ability to distort in a controlled way.

\section{REFERENCES}

1. Avraam M.T. (2009): MR-fluid brake design and its application to a portable muscular rehabilitation device, $\mathrm{PhD}$ thesis, Active Structures Laboratory Department of Mechanical Engineering and Robotics, Universite Libre de Bruxelles.

2. Bajkowski J. (2004), Modeling, mathematical description, simulation and experimental research of magnetorheological damper with influence of temperature, Machine Dynamic Problems, 28(3), 9-15.

3. Bajkowski J. (2014), Magnetorheological fluids and dampers, Properties, structure, investigations, modeling and applications, Transport and Communication Publishers, Warsaw (in Polish).

4. Bajkowski J., Bajkowski M., Zalewski R. (2007), L'influence de la temperature sur le travail d'un amortiseur magnetorheologique, XV French-Polish Seminar of Mechanics, France.

5. Bajkowski J., Grzesikiewicz W., Holnicki J., Parafiniak M., Wolejsza Z. (2005), Analysis of the influance of magnetorheological damper on the airplane chassis during landing, ECOMAS, Lizbona.

6. Bajkowski M. (2006), Analysis of the influence of selected characteristics of a magnetorheological damper on change of dynamic properties of special object model, PhD dissertation, Warsaw University of Technology, SiMR, Warsaw.

7. Barvosa-Carter W., Johnson N.L., Browne A.L. (2006), Reversibly expandable energy absorbing assembly utilizing actively controlled and engineered materials for impact management and methods for operating the same, US patent 7.140.478 B2.

8. Bazinenkov A., Valery P. Mikhailov V.P. (2004), Active and semi active vibration isolation systems based on magnetorheological materials, Procedia Engineering, 106, 170-174.

9. Brei D., Redmond J., Wilmont A.L., Browne N.A., Johnson N.L., Jones G.L. (2006), Hood lift mechanisms utilizing active materials and methods of use, EU patent EP $1617022 \mathrm{~A} 2$.

10. Carlson J. D. (2001), What makes a good MR fluid?, Proceedings of the Eighth International Conference, Electrorheological Fluids and Magnetorheological Suspensions.

11. Carlson J.D. (1999), Low-cost MR fluid sponge devices, Proceeding of the $7^{\text {th }}$ international conference on ER fluids and MR suspensions, World Scientific Publishing Co. Pte. Ltd., Honolulu Hawaii.

12. Carlson J.D., Jolly M.R. (2000), MR fluid, foam and elastomer devices, Mechatronics, 10, 555-569.

13. Carlson J.D., Weiss K.D. (1994), A growing attraction to magnetic fluids, Machine Design, 8, 61-66.

14. Dyke S.J., Spemcer B.F., Sain M.K., Carlson J.D. (1998), An experimental study of MR dampers for seismic protection, Smart Mater Struct., 7, 693-703.
15. Dyke S.J., Spencer B.F., Sain M.K., Carlson J.D. (1996), Modeling and control of magnetorheological dampers for seismic response reduction, Smart Materials and Structures, 5(5), 565-575.

16. Elie L.D., Ginder J.M., Mark J.S., Nichols M.E., Stewart W.M. (1999), Method for allowing rapid evaluation of chassis elastomeric devices in motor vehicles, US patent 5.974.856.

17. Fang F.F., Jang I. B., Choi H.J. (2007), Single-walled carbon nanotube added carbonyl iron suspension and its magnetorheology, Department of Polymer Science and Engineering, Inha University, Incheon, 402-751, Republic of Korea.

18. Flores G.A., Liu J. (2002), In-Vitro blockage of a simulated vascular system using magnetorheological fluids as a cancer therapy, European Cells and Materials, 3, 9-11.

19. Forte P., Paternò M., Rustighi E. (2004), A Magnetorheological Fluid Damper for Rotor Applications, International Journal of Rotating Machinery, 10(3), 175-182.

20. Genc S. (2002), Synthesis and properties of magnetorheological (MR) fluids, PhD dissertation, University of Pittsburgh.

21. Goncalves F.D. (2005), Characterizing the behavior of magnetorheological fluids at high velocities and high shear rates, $\mathrm{PhD}$ thesis, Virginia Polytechnic, Blacksburg.

22. Gordaninejad F., Sahdi M., Hansen B.C., Chang F.K. (2002), Magneto-rheological fluid dampers for control of bridges, J. of Int. Material Systems and Structures, 13, 167-180.

23. Griffin M.J., Wu X. (1998), The influence of end-stop buffer characteristics on the severity of suspension seat-stop impacts, Journal of sound and vibration, 215(4), 989-996.

24. Hiemenz G., Wereley N. (1999), Seismic response of civil structures utilizing seni-active MR and ER bracing systems, Journal of intelligent material systems and structures, Vol 10, Issue 8, 646-651.

25. Imthiyaz T.A, Sundarrajan R., Prasaath G.T., Raviraj V. (2014), Implementation of Magneto-rheological Dampers in Bumpers of Automobiles for Reducing Impacts during Accidents, Procedia Engineering, 97, 1220-1226.

26. Kaleta J. (2013), Magnetic Materials SMART: Structure, manufacturing, investigations, properties, applications, Publishing House of Wroclaw University of Technology, (in Polish).

27. Kaleta J.Z., Lewandowski D. (2007), Inelastic properties of magnetorheological composites: I. Fabrication, experimental tests, cyclic shear properties, Smart Materials Structures, 16, 1948-1953.

28. Kaleta J.Z., Lewandowski D., Ziętek G. (2007), Inelastic properties of magnetorheological composities: II: Model identification of parameters, Smart Materials and Structures, 16, 1954-1960.

29. Kikuchi T., Ikeda K., Otsuki K., Kakehashi, Furusho J. (2009), Compact MR fluid clutch device for human-friendly actuator, Journal of Physics, 149, 1-4.

30. Kikuchi T., Otsuki K., Furusho J., Abe H. (2010), Design and development of compact magnetorheological fluid clutch (CMRFC) with Multi-layered disks and micro-sized gaps, Journal of the Society of Rheology, 38, 17-22.

31. Klukowski C. (2009), Steering column for a motor vehicle, US patent 20090033082 A1.

32. Lee H.G., Sung K.G., Chois S.B. (2009), Ride comfort characteristics with different tire pressure of passenger vehicle featuring MR damper, Journal of Physics, 149, 1-4.

33. Lee U., Kim D., Jeon D. (1999), Design analysis and experimental evaluation of an ER and MR clutch, Journal of intelligent materials and structures, Vol 10, Issue 9, pp. 701-707.

34. Li W.H., Zhang X.Z., Du H. (2013), Magnetorheological elastomers and their applications, University of Wollongong, Research Online

35. Li Y., Li J., Li W.,Du, H. (2014), A state-of-the-art review on magnetorheological elastomer devices, Smart Materials and Structures, 23(12), 1-24.

36. Li Z.X., Yu Chen Y., Yun-Dong Shi Y. (2016), Seismic damage control of nonlinear continuous reinforced concrete bridges under extreme earthquakes using MR dampers, Soil Dynamics and Earthquake Engineering, 88, 386-398. 
37. Milecki A. (2001), Investigation and control of magneto-rheological fluid dampers, International journal of machine tools \& manufacture, 41, 379-391.

38. Milecki A. (2004), Modeling of magneto-rheological schock absorbers, Archiwum technologii maszyn i automatyzacji (In Polish), Vol 24, no. 2, 123-129.

39. Milecki A., Lawniczak A. (1999), Electro- and Magnetorheological fluids and their applications in technics, Publishing house of Poznan University of Technology (in Polish).

40. Muc A., Barski M. (2007), Magnetorheological fluids and their practical applications, Publishing house of Cracow University of Technology (in Polish).

41. Nyawako D., Reynolds P. (2007), Technologies for mitigation of human - induced vibrations in civil engineering structures, The shock and vibration digest, 39(6), 465-493.

42. Olabi A. G., Grunwald A. (2007), Design and application of magneto-rheological fluid, Materials and Design, 28, 2658-2664.

43. Ottaviani R.A., Ulicny J.C., Golden M.A. (2006), Magnetorheological nanocomposite elastomer for releasable attachment applications, US patent 6.877.193 B2.

44. Park Ch., Jeon D. (2002), Semiactive vibration control of a smart seat with an MR fluid damper considering its time delay, Journal of intelligent material systems and structures, 13, 521-524.

45. Park E. J., Falcao L., Suleman A. (2008), Multidisciplinary design optimization of an automotive magnetorheological brake design, Computers and Structures, 86, 207-216.

46. Poynor J. C. (2001), Innovative Designs for Magneto-Rheological Dampers, master thesis, Virginia Polytechnic, Blacksburg.

47. Rabinow J. (1948), The magnetic fluid clutch, AIEE Transactions, 67: 1308-1315.

48. Rabinow J. (1951), Magnetic fluid torque and force transmitting device, U.S. Patent 2, 575.

49. Sapiński B. (2006), Magnetorheological dampers in vibration control, AGH University of Science and Technology Press, Kraków

50. Sapiński B., Snamina J. (2007), Cable - MR damper system motion in transients, Mechanics 26, 22-29.

51. Sapiński B., Snamina J., Maślanka M, Rosół M. (2006), Facility for testing of magnetorheological damping systems for cable vibrations, Mechnics, 25/3, 135-

52. Sassi S., Cherif K., Mezghani L., Thomas M., Kotrante A. (2005), An innovative magnetorheological damper for automotive suspension: from design to experimental characterization, Smart Mater. Struct., 14, 811-822.

53. Schwartz M. (2009), Smart Materials, Taylor and Francis Group

54. Skalski P (2014), Morphing Structure with a Magnetorheological Material - Preliminary Approach, Mechatronics 2013 Recent Technological and Scientific Advanced. Springer International Publishing, 219-226.

55. Skalski P., Parafiniak M., Wysokiński D., Bednarski M. (2014), Aerodynamic profile with elastic skin of active material, P-409202, Polish patent, 29.02.2016.
56. Skorupka Z. (2010), Magnetorheological fluids as method for active controlling of landing gear shock absorber characteristic, Transactions of the Institute of Aviation, 207, 36-48.

57. Spaggiari A. (2013), Properties and applications of Magnetorheological fluids, Dept. of Engineering Sciences and Methods, University of Modena and Reggio Emilia, Italy.

58. Spencer B. F., Tomizuka M., Yun C. B., Chen W. M., Chen R. W. (2007) World Forum on Smart Materials and Smart Structures Technology, Proceedings of the World Forum on Smart Materials and Smart Structures Technology, Taylor \& Francis Group, 291-294.

59. Stewart W.M., Ginder J.M., Ellie L.D., Nicholas M.E. (1998), Method and apparatus for reducing brake shudder, US patent 5.816.587.

60. Szeląg W., Nowak L., Myszkowski A. (2000), Electromagnetic brake with magnetorheological fluid, Scientific Works of the Institute of Electric Machines, Drives and Measurements, 48, 206-213.

61. Tao R. (2011), Electro-Rheological Fluids And Magneto-Rheological Suspensions, Proceedings of the 12th International Conference, World Scientific, Singapure, 748.

62. Thorarinsson E. T., Jonsdottir F., Palsson H. (2006), Design of a Magnetorheological Prosthetic Knee, Department of Mechanical Engineering, University of Iceland.

63. Watson J.R. (1997), Method and apparatus for varying the stiffness of a suspension busing, US patent 5.609.353.

64. Xiao-min D., Yu Miao, Liao C., Chen W. ( 2009), A new variable stiffness absorber based on magneto-rheological elastomer, Transactions of Nonferrous Metals Society of China, 19, 611-615.

65. Yoon S.-S., Kang S., Kim S.J., Kim Y.-H., Kim M., Lee C. (2003), Safe arm with MR-based passive compliant joints and visco-elastic covering for service robot applications, Intl. Conference on Intelligent Robots and Systems, October, Nevada, 2191-2196.

66. BWI Group.com, MAGNERIDE ${ }^{\mathrm{TM}}$ CONTROLLED SUSPENSION SYSTEM (2013), http://www.bwigroup.com/en/pshow.php?pid=22; 08.08.2016.

67. BWI Group.com, MAGNETO-RHEOLOGICAL MOUNTS (2013) http://www.bwigroup.com/en/pshow.php?pid=26; 08.08.2016.

68. Carlson J.D. (2002), http://www.sensorsmag.com/sensors/electricmagnetic/controlling-vibration-with-magnetorheological-fluiddamping-999; 08.08.2016.

69. http://robohub.org/icelands-ossur-wins-popsci-best-of-whats-newaward-for-symbionic-leg/; 08.08.2016.

70. https://www.dywidag-systems.com/emea/projects/projectdetails/article/dr-franjo-tudjmann-bridge-dubrovnik-croatia.html; 08.08.2016.

71. Magneto-Rheological (MR) Fluid, "LORD is proud to be the exclusive supplier of MR Fluid technology..." Retrieved from: http://www.lord.com/products-and-solutions/active-vibrationcontrol/industrial-suspension-systems/magneto-rheological-(mr)-fluid; 08.08.2016. 